\title{
Ortaokul Yedinci ve Sekizinci Sınıf Öğrencilerinin Cebirsel İfadeler Konusundaki Başarı Performanslarının İncelenmesi*
}

\author{
Investigation of $7^{\text {th }}$ and $8^{\text {th }}$ Grade Students' Performance about \\ Algebraic Expressions \\ Osman BIRGIN*** Kayhan DEMİÖREN ${ }^{* * *}$ \\ • Geliș Tarihi: 20.05 .2019 • Kabul Tarihi: 06.02.2020 • Cevrimiçi Yayın Tarihi: 10.02.2020
}

\begin{abstract}
$\ddot{\mathbf{O z}}$
$\mathrm{Bu}$ araştırmanın amacı, ortaokul yedinci ve sekizinci sınıf öğrencilerinin cebirsel ifadeler konusundaki başarı performanslarını incelemektir. Araştırmada tarama yöntemi kullanılmıştır. Araştırmanın çalışma grubunu Afyonkarahisar ilinde yedinci ve sekizinci sınıfta öğrenim gören toplam 180 ortaokul öğrencisi oluşturmaktadır. Veri toplama aracı olarak 7 alt boyuttan oluşan 28 soruluk çoktan seçmeli bir cebir testi kullanılmıştır. Bu araştırmada verilerin analizinde SPSS 17.0 paket programı kullanılmış, değişkenlere bağlı olarak bağımsız örneklemler t-testi ve Pearson korelasyon testi yapılmıştır. Araştırma sonucunda öğrencilerin cebirsel ifadeler konusundaki başarı performanslarının orta düzeyde olduğu, en düşük başarı performansının 'Basit görsel ve cebirsel ifadelerin anlamını açıklama' konusunda, en yüksek başarı performansının ise 'Cebirsel ifadelerle toplama ve çıkarma yapma' konusunda olduğu saptanmıştır. Bu araştırmada 8. sınıfların cebir performanslarının 7. sınıflara göre daha yüksek olduğu, ancak cinsiyete göre anlamlı fark göstermediği tespit edilmiştir. Öğrencilerin cebirsel ifadelerdeki başarı performanslarının matematik başarısını olumlu yönde etkilediği belirlenmiştir.
\end{abstract}

Anahtar sözcükler: Matematik, 7. ve 8. sınıf öğrencisi, Cebirsel düşünme, Cebirsel ifadeler, Cebir performans1

Atıf:

Birgin, O. ve Demirören, K. (2020). Ortaokul yedinci ve sekizinci sınıf öğrencilerinin cebirsel ifadeler konusundaki başarı performanslarının incelenmesi. Pamukkale Üniversitesi Eğitim Fakültesi Dergisi, 50, 99-117.doi: 10.9779/pauefd.567616

\footnotetext{
* Bu çalışma, 14-16 Eylül 2017 tarihlerinde Uşak Üniversitesi’nde düzenlenen I. Uluslararası Eğitim Araştırmaları ve Öğretmen Eğitimi Kongresi'nde sözlü bildiri olarak sunulmuş olup 2.yazarın yüksek lisans tezinden üretilmiştir.

*** Prof. Dr., Uşak Üniversitesi, Eğitim Fakültesi, Matematik ve Fen Bilimleri Eğitimi Bölümü, Uşak.

E-posta: osman.birgin@ usak.edu.tr, ORCID: https://orcid.org/0000-0003-3460-2731

${ }^{*}$ Şemsettin Karahisari Ortaokulu, Afyonkarahisar. E-posta:
https://orcid.org/0000-0001-8862-2899
https://orcid.org/0000-0001-8862-2899
} 


\begin{abstract}
The aim of this study is to examine the seventh and eighth grade students' performance about algebraic expressions. Survey method was used in this study. The study group consists of 180 secondary school students studying in the seventh and eighth grade in Afyonkarahisar province. As a data collection tool, a 28-item multiple-choice algebra test consisting of 7 sub-dimensions was used. In this study, SPSS 17.0 package program was used for analyze the data and independent samples t-test and Pearson correlation test were used according to variables. At the end of the research, it was found that the students' achievement performance on algebraic expressions was at medium level and the lowest achievement performance was about 'explaining the meaning of simple visual and algebraic expressions' and the highest achievement performance was about 'adding and subtracting with algebraic expressions'. In this study, it was also determined that eighth grade students' performance about algebra were higher than those of the seventh grade students, but did not found a significant difference according to gender. It was determined that students' performance in algebraic expressions had a positive effect on mathematics achievement.
\end{abstract}

Keywords: Mathematics, 7th and 8th grade students, Algebraic thinking, Algebraic expressions, Algebra performance

\title{
Cited:
}

Birgin, O. ve Demirören, K. (2020). Investigation of $7^{\text {th }}$ and $8^{\text {th }}$ grade students' performance about algebraic expressions. Pamukkale Üniversitesi Ĕgitim Fakültesi Dergisi, 50, 99-117.doi: 10.9779/pauefd.567616 


\section{Giriş}

Matematik, bireylerin günlük yaşamlarını sürdürmesinde gerekli olan temel bilgi ve becerilerin kazanılmasında önemli bir rol üslenmektedir. Özellikle ilkokul ve ortaokul seviyesinde kazanılan işlem becerisi, öğrenilen kavram ve kurallar her birey için gerekli olan temel bilgileri içermektedir (Ersoy, 1997). Bu temel bilgilerden biri de cebir öğrenme alanıdır. Matematiğin özel bir dalı olan cebir, cebirsel düşünme becerinin yanında akıl yürütme ve muhakeme edebilme becerisini gerekli kılmaktadır. Üstelik çoğu zaman farkında olmadan bireyler günlük hayatta birçok bilgiyi ve durumu analiz ederken cebir ve cebirsel düşünmeyi kullanmaktadırlar (Davidenko, 1997). Bu nedenle cebirsel düşünme becerisi tüm öğretim kademesi ve sınıf düzeyleri için önemli görülmektedir (NCTM, 2000). Cebir ile ilgili en eski bilgilere M.Ö. 17001600'den kalan eski Mısır papirüslerinde rastlanılmaktadır. Rhind papirüsünde çok sayıda birinci dereceden bir bilinmeyenli denklemlere ve çözümlerine rastlanmaktadır. Mısırlıların, birinci dereceden bir bilinmeyenli denklemlerin çözümlerinde yanlışı deneme yolunu kullandıkları görülmektedir. Bu yöntem 15. ve 16. yüzyıllarda eski Mısır dışında, Hintliler ve İslam dünyası matematikçileri tarafından da kullanılmıştır. Babilliler, eski Mısır'daki cebir anlayışından daha ileri giderek, ikinci dereceden denklemler ve doğrusal denklem sistemlerinin çözümleriyle ilgilenmişlerdir (Baki ve Bütüner, 2013). Takip eden süreçte eski Yunan matematikçilerinin cebir ile geometriyi birlikte kullanmalarına (Yenilmez ve Avcu, 2009) karşın Harezmi başta olmak üzere 8.-15.yy Türk-İslam Dünyası matematikçilerinin cebir alanına yaptığı önemli katkılar ile cebir alanının temelleri atılmıştır (Baki, 2008). Genel olarak cebir, sayıları ve sembolleri kullanarak araştırılan ilişkiyi genelleyerek denkleme dönüştürmemizi sağlayan önemli matematik dalıdır (Akkaya ve Durmuş, 2006). Matematik alanındaki yeni gelişmelerle birlikte cebire yönelik bakış açısı değişmiş; cebir, düşünceleri ve ilişkileri ifade etme yöntemi olarak görülmeye başlanmıştır (Akkaya, 2006).

Cebir konularının temelinde "değişken" ve "eşitlik" olarak iki kavram yer almaktadır. Cebir, değişkenleri anlama ve onlarla işlem yapma ile ilgilenir. Aritmetiğin temelinde rakamlar, sayılar yer alırken; cebirin temelinde değişkenler yer almaktadır. Bu nedenle değişken kavramı, aritmetikten cebire geçişte, ileri matematiksel konu ve kavramların öğrenilmesinde önem arz etmektedir (Schoenfeld ve Arcavi, 1988). Cebirin dili olarak kabul edilen değişkenlerin temel seviyede iyi öğrenilmesi ileriki düzeyde cebir başarısını etkilemektedir. Değiş̧ken kavramını kavramsal olarak öğrenmeyen bir öğrencinin cebirsel ifadeleri öğrenmede zorlanması, cebir öğrenmeye isteksiz olması ve olumsuz tutum benimsemesi söz konusudur. Yapılan birçok araştırma (Akkan, 2009; Akkaya ve Durmuş, 2006; Davidenko, 1997; Dede, Yalın ve Argün; 2002; English ve Warren, 1998; Kar, Çiltaş ve Işık, 2011; Kaya, 2017; Macgregor ve Satcey, 1997) değişkenlerin cebirde önemli bir yere sahip olduğunu ancak öğrencilerin değişkenleri anlamada zorlandıklarını göstermektedir. Akkan ve Baki (2016), Behr, Erlwanger ve Nichols (1980), Hersovics ve Linchevski (1994) ve Linchevski (1995) yaptıkları araştırmalarda bazı öğrencilerin "eşittir işaretini”" kavramsal düzeyde anlamada bilişsel bir boşluğun oluştuğunu (eksik öğrenmelerinin) ve yanılgılarının olduğunu belirlemişlerdir. Değişken ve eşitlik kavramlarındaki bu tür eksikliklerin öğrencilerin aritmetikten cebire geçişi engelleyen önemli bir etken olduğu vurgulanmaktadır. Öğrenciyi sistemli olarak hataya götüren ve öğrencinin yaptığı hataların çoğunun arka planında kavram yanılgıları bulunmaktadır (Bingölbali ve 
Özmantar, 2010). Bu yanılgıların erken tespiti ve önlenmesi için değişken ve eşitliği doğru kavramanın önemli olduğu düşünülmektedir.

Denklemler, matematik öğretim programının 6.sınıfında öğrencilerin karşılaştıkları ve aritmetikten cebire geçişi temel teşkil eden konulardandır. Denklemler öğrencilerin günlük hayat problemlerine çözüm üretmesinin yanında, düzenli ve sistemli bir şekilde problem çözümüne yardım etmektedir (Köroğlu, Geçer, Taş̧̧1, \& Ay, 2004). Değişken ve eşitliği kavrayan bir öğrencinin denklemleri öğrenmesi kolaylaşmaktadır. Ancak bu düşünüldüğü kadar kolay bir süreç olmayıp denklemlere geçişte öğrencilerin yaşadıkları birçok zorluk söz konusudur. $\mathrm{Bu}$ zorluklar arasında sözel problemleri denklemlere dönüştürmedeki zorluklar (Bernardo \& Okagaki, 1994; Linchevski \& Hersovics, 1996), harfleri veya çeşitli gösterim şekillerini matematiksel ifade etmedeki zorluklar (Baki ve Kartal, 2004; Erdem, 2013; Kieran, 1992; Yıldızhan ve Şengül, 2017), aritmetiksel kurallardan cebirsel kurallara geçişteki zorluklar (Akkan, 2010), eşitlik ve değişken kavramının anlaşılmasındaki zorluklar (Akkan ve Baki, 2016; Dede ve Argün, 2003; Falkner, Levi \& Carpenter, 1999) yer almaktadır. Herscovics ve Linchenski (1994) öğrencilerin yaşadıkları bu zorlukları, aritmetikten cebire geçişte oluşan bilişsel boşlukla açıklamıştır. Bu bağlamda aritmetikten cebire geçiş sürecindeki bu zorluğu aşmak amacıyla cebir öncesi döneme vurgu yapan pek çok çalışma vardır (Akkan, Baki ve Çakıroğlu, 2012; Kieran, 1992; Kieran \& Chalouh, 1993; Londholz, 1993; Van Amerom, 2002).

Öğrencilerin cebirde yaşadıkları sorunları incelemek amacıyla Akarsu (2013), 7.sınıf öğrencilerinin cebir öğrenme alanında matematiksel dil kullanımlarını incelemiştir. Araştırmasında, öğrencilerin cebir öğrenme alanında önemli eksiklikleri olduğunu, matematiksel dil kullanım becerilerinin yeterli düzeyde olmadığını ve bazı kavram yanılgılarına sahip olduklarını belirlemiştir. Ayrıca öğrencilerin matematiksel dili anlayabilme ve kullanabilme düzeyleri ile matematik başarıları arasında orta düzeyde, pozitif yönlü anlamlı bir ilişki saptamıştır. Akkaya ve Durmuş (2006) altıncı sınıf öğrenciler üzerinde yaptıkları araştırmada öğrencilerin cebirde harflerin kullanımı anlamada, değişken ve eşitlik kavramı ile ilgili bazı kavram yanılgılarının olduğu tespit etmiştir. Akkan ve Baki (2016), 5-8.sınıfta öğrenim gören farklı sınıf seviyelerindeki öğrencilerinin aritmetikten cebire geçiş süreçlerini, sembollerin kullanımı ve harflerin anlamını yorumlama becerilerini araştırmıştır. Araştırma sonucunda ortaokul öğrencilerin genel olarak eşittir işaretini işlemsel bir sembol olarak algıladıkları, harflerin farklı kullanımı ve anlamı ile ilgili birçok zorluk yaşadıkları, bunun ise öğrencilerin aritmetikten cebire geçişlerini olumsuz yönde etkilediği belirlenmiştir. Ayrıca farklı öğrenim seviyelerindeki öğrencilerin öğrenim seviyeleri arttıkça aritmetikten cebire geçişin olumlu yönde değiştiği ve geliştiği, ancak bu gelişmenin yeterli olmadığ saptanmıştır. Kaya ve Keşan (2014) yaptıkları alanyazın taraması çalışmasında ilköğretim seviyesindeki öğrencilerin cebirsel düşünme ve muhakeme etme becerisi ile cebirsel işlem yürütme becerilerinin yetersiz olduğunu, matematiksel bilgileri ilişkilendirmede zorlandıklarını ve günlük yaşam durumları arasında bağlantı kuramadıklarını belirlemişlerdir. Yenilmez ve Avcu (2009) altıncı sınıf öğrencilerinin cebir öğrenme alanındaki başarı düzeylerini inceledikleri çalışmada öğrencilerin eşitliğin gösterimi ve korunumu sorularında problem yaşamadıklarını, ancak denklem kurma ve kurulan denklemi çözme konusunda zorluk çektiklerini saptamışlardır. Kaya, Keşan, İzgiol ve Erkuş (2016) yaptıkları araştırmada yedinci sınıf öğrencilerinin cebirsel muhakeme becerilerine yönelik başarı performanslarını incelenmişlerdir. Araştırma sonucunda öğrencilerin cebirsel yapıları/ilişkileri tanıma ve kullanma becerileri dışında, aynı verinin farklı cebirsel ifadelerini 
kullanma, uygun cebirsel muhakemeyi belirleme, cebirsel ifadelere yönelik çıkarımda bulunma, çıkarıma yönelik cebirsel işlemler yapma, sonucun doğruluğuna ve çözüm yoluna karar verme ile rutin olmayan problemleri çözme becerilerine ait test puanlarının düşük ya da orta düzeyde olduğu belirlenmiştir. Ayrıca tüm alt boyutlarda kız ve erkek öğrencilerin cebirsel muhakeme becerileri arasında anlamlı bir fark saptanmamıştır. Dede, Yalın ve Argün (2002) sekizinci sınıf öğrencileri üzerinde yaptıkları araştırmada öğrencilerin değişken kavramında sahip oldukları yanlış anlama ve hataların nedenlerini; değişkenin farklı ifade edilişlerini bilememe, kullanılan değişkenler ile yapılan genellemelerin farkında olamama, değişkenin matematiğin çeşitli bilim dallarındaki temsil çeşitlerini bilememe, matematikte daha önceden öğrenilen bilgileri yanlış transfer etme ve değişken kullanarak işlem yapmadaki eksiklikler olarak sınıflandırmışlardır. Benzer şekilde Şimşek ve Soylu (2018), yedinci sınıf öğrencilerinin cebirsel ifadeler konusunda yaptıkları hataların nedenlerini inceledikleri araştırmada öğrencilerin cebirsel ifadeler konusundaki bilgilerinin istenilen düzeyde olmadığını ve birçok hata yapıldığını saptamışlardır. Yapılan bu hatalar arasında öğrencinin değişkeni görmezden gelmesi, verilen cebirsel ifadeyi denkleme dönüştürerek çözmesi, soruda verilen değişken yerine $\mathrm{x}$ değişkenini kullanması ve verilen probleme uygun denklemi yanlış kurması yer almaktadır. Bu hataların nedeni olarak öğrencinin işlem içindeki değişkene bir anlam yükleyememiş olması, bilinmeyen ile değişken kavramlarını ayırt edememesi, değişken ifadesini $\mathrm{x}$ ifadesi ile özdeşleştirmiş olması, aritmetiksel işlemlerdeki bilgi eksikliği ve cebir konusuna ayrılan zamanın yetersiz olması tespit edilmiştir.

Ülkemizdeki matematik dersi öğretim programı incelendiğinde cebir konuları aritmetik ve geometri konularından sonra yer aldığı dikkat çekmektedir. Üstelik cebir öğretimi ve öğrenimi ilkokulda aritmetikten başlayarak ortaokulda denklemler, lisede ise fonksiyon bilgilerine kadar geniş bir alanı içine alan almaktadır (Kaya ve Keşan, 2014). Ülkemizde 4+4+4 eğitim sistemine geçişle birlikte 6 . sınıf düzeyinde cebirle tanışan öğrencilerin 7 . ve 8 . sınıflarda cebir öğrenme alanıyla ilgili kazandıkları bilgi ve becerileri ortaöğretime başarılı bir şekilde taşıyabilmeleri oldukça önemlidir. Üstelik cebirsel düşünme ve işlem yapabilme performansları öğrencilerin yaratıcılık ve problem çözme becerilerinin gelişimine olumlu yönde katk1 sağlamaktadır. $\mathrm{Bu}$ bağlamda ortaokul düzeyindeki öğrencilerin aritmetikten cebire geçişi sürecini tamamlamaları, cebirsel işlemler ve cebirsel düşünme ve muhakeme becerisini kazanmaları beklenmektedir. Bu nedenle bu araştırmanın amacı, ortaokul yedinci ve sekizinci sınıf öğrencilerinin matematik dersi cebirsel ifadeler konusundaki performanslarını incelemektir. Bu kapsamda aşağıdaki sorulara cevap aramaktır:

a) Ortaokul öğrencilerinin cebirsel ifadeler konusundaki başarı performansları ne düzeydedir?

b) Ortaokul öğrencilerinin cebirsel ifadeler konusundaki başarı performansları cinsiyet ve sinıf düzeyine göre anlaml fark göstermekte midir?

c) Ortaokul öğrencilerinin cebirsel ifadeler konusundaki başarı performansları ile matematik dersi başarıları arasında anlamlı ilişki var mıdır?

\section{Yöntem}

$\mathrm{Bu}$ araştırma, betimsel tarama modeli temel alınarak yürütülmüştür. Betimsel tarama modelinde araştırılacak olan konu, birey, nesne kendi koşulları içinde olduğu gibi betimlenmeye ve 
açıklanmaya çalışlır. Bu yönüyle geçmişte ya da halen var olan bir durumu olduğu şekli ile betimlemeyi amaçlayan araştırmalar için oldukça uygundur (Karasar, 2004). Bu yönüyle ortaokul 7. ve 8.sınıf öğrencilerinin cebirsel ifadeler konusundaki başarı performans düzeylerinin belirlenmeye çalışıldığı bu araştırma, betimsel tarama niteliğindedir.

\section{Çalışma Grubu}

$\mathrm{Bu}$ araştırmanın çalışma grubunu Afyonkarahisar il merkezinde 7. ve 8.sınıfta öğrenim görmekte olan toplam 180 ortaokul öğrencisi oluşturmaktadır. Çalışma grubunun 87'si $(\% 48,3)$ kız, 93'ü (\%51,7) erkek öğrenci olup, 90’ı (\%50) yedinci sınıfta, 90’ı (\%50) sekizinci sınıfta öğrenim görmektedir.

\section{Veri Toplama Araçları}

$\mathrm{Bu}$ araştırmada veri toplama aracı olarak araştırmacılar tarafindan geliştirilen "Bireysel Bilgi Formu" ve "Cebirsel Iffadeler Başarı Testi (CBT)" kullanılmıştır.

\section{Bireysel Bilgi Formu:}

Bireysel bilgi formu araştırmaya katılan öğrencilerin demografik bilgilerini almak amacıyla tasarlanmış, cinsiyet, sınıf, okul ve matematik karne notlarına ilişkin bilgiler yer almaktadır.

\section{Cebirsel Iffadeler Başarı Testi (CBT):}

$\mathrm{Bu}$ araştırma kapsamında araştırmacılar tarafindan geliştirilen CBT, 28 çoktan seçmeli sorudan ve 7 alt boyuttan oluşmaktadır. CBT'nin geliştirilmesi sürecinde matematik dersi öğretim programının kazanımları dikkate alınmış, alan yazındaki çeşitli araştırmalardan (Akkan ve Baki, 2016; Akkaya ve Durmuş, 2006; Baysal, 2010; Ersoy ve Erbaş, 2005; Herscovics ve Linchevski, 1994; Gülpek, 2006; Linchevski, 1995; Perso, 1992; Yenilmez ve Avcu, 2009), MEB'nin matematik ders kitapları ve yardımcı kitaplardan yararlanılmıştır. CBT'deki maddeler 6-7.sınıf matematik dersi öğretim programlarında yer alan 7 farklı kazanım 'Sözel olarak verilen bir duruma uygun cebirsel ifade yazar', 'Cebirsel ifadeye uygun sözel durum yazar', 'Cebirsel ifadelerle toplama ve çıkarma yapar', 'Birinci dereceden bir bilinmeyenli denklemleri çözer', 'Basit cebirsel ifadeleri anlar, farklı biçimlerde yazar', 'Cebirsel ifadenin değerini değişkenin alacağı farklı doğal sayı değerleri için hesaplar', 'Görsel ifadeden cebirsel ifadeye geçiş' dikkate alınarak oluşturulmuştur. CBT’nin içeriği ve öğrenci düzeyine uygunluğu için 2 alan uzmanın ve 3 matematik öğretmenin görüşü alınmıştır. Alınan görüşler doğrultusunda bazı maddelerin ifadelerinde ve görsellerinde düzenleme yapılmış, 3 madde ise görüşler doğrultusunda testten çıkarılmıştır. Taslak 32 çoktan seçmeli sorudan oluşan CBT'nin madde analizi amacıyla 86 sekizinci sınıf öğrenci üzerinde pilot çalışması yapılmıştır. Pilot çalışma sonucunda CBT'nin maddelerin güçlük indekslerinin 0.16 ile 0.89 arasında değer aldığı belirlenmiştir. Madde ayırt edicilik bakımından 0.20'den küçük olan 3 madde testten çıkarılmış, madde ayırt ediciliği 0.20 ile 0.30 arasında yer alan bir madde ise CBT'nin her bir alt boyutlarında yer alan madde sayısını (4 madde) eşitlemek amacıyla çıkartılmasına karar verilmiştir. Böylece toplam 28 çoktan seçmeli soru ve 7 alt boyuttan oluşan CBT'nin madde ayırt edicilik indekslerinin 0.32-0.56 arasında değer aldığı belirlenmiştir. Pilot çalışmada CBT'nin KR-20 güvenirlik katsayısı 0.84 olarak hesaplanmıştır. Bu yönüyle testten elde edilen ölçümlerin güvenilir olduğuna karar verilmiştir. Bu araştırma kapsamında CBT’nin KR-20 güvenirlik katsayısı 0.81 olarak hesaplanmıştır. 


\section{Bulgular}

\section{Yedinci ve Sekizinci Sınıf Öğrencilerinin CBT Başarı Performanslarına İlişskin Bulgular}

Yedinci ve sekizinci sınıf öğrencilerinin CBT ve alt boyutları bakımından başarı performanslarının betimsel istatistik değerleri Tablo 1'de sunulmuştur.

Tablo 1. Öğrencilerin CBT Performansına İlişkin Betimsel İstatistik Değerleri (n=180)

\begin{tabular}{lcc}
\hline CBT'nin Alt Boyutları & $\bar{x}$ & SS \\
\hline Sözel ifadeden cebirsel ifadeye geçiş & 2.27 & 1.06 \\
Cebirsel ifadeden sözel ifadeye geçiş & 2.04 & 1.23 \\
Cebirsel ifadelerde toplama ve çıarma & 2.34 & 1.06 \\
1.dereceden bir bilinmeyenli denklemi çözme & 2.03 & 1.34 \\
Cebirsel ifadeleri farklı biçimde yazma & 1.88 & 1.32 \\
Değişkene ait farklı değerleri hesaplama & 2.23 & 1.26 \\
Görsel ifadeden cebirsel ifadeye geçiş & 1.77 & 1.13 \\
CBT’nin Tümü & 14.60 & 5.82 \\
\hline
\end{tabular}

Tablo 1 incelendiğinde ortaokul öğrencilerinin CBT kapsamında en iyi başarı performans1 "Cebirsel ifadelerde toplama ve çıkarma" ( $\bar{x}=2.34, \mathrm{SS}=1.06)$, "Sözel ifadeden cebirsel ifadeye geçiş" ( $\bar{x}=2.27, \mathrm{SS}=1.06)$ ve "Değişkene ait farkl değerleri hesaplama" $(\bar{x}=2.23, \mathrm{SS}=1.26)$ alt boyutlarında, en düşük cebir başarı performansını "Basit cebirsel ve görsel ifadeleri açılama" ( $\bar{x}=1.77, \mathrm{SS}=1.13)$ ve "Cebirsel ifadeleri farklı biçimde yazma" $(\bar{x}=1.88, \mathrm{SS}=1.32)$ alt boyutlarında gösterdikleri anlaşılmaktadır. Ortaokul öğrencileri "cebirsel ifadeden sözel ifadeye geçiş" ( $\bar{x}=2.04, \mathrm{SS}=1.23)$ ve "1.dereceden bir bilinmeyen denkleri çözme" ( $\bar{x}=2.03, \mathrm{SS}=1.34)$ konusunda orta düzeyde başarı göstermişlerdir. Öğrencilerin genel olarak cebirsel ifadeler konusunda başarı performanslarının orta düzeyde olduğu $(\bar{x}=14.60$, SS=5.82), öğrencilerin cebirsel ifadeler konusunda aritmetik işlemlerin ön planda olduğu alt boyutlarda (kazanımlarda) daha başarılı iken, soyut düşünme ve görselleştirme gerektiren kazanımlarda daha başarısız oldukları söylenebilir.

\section{Öğrencilerin Cinsiyete Göre CBT Başarı Performanslarına İlişkin Bulgular}

Ortaokul öğrencilerin CBT puanlarının cinsiyet bakımından anlamlı bir fark olup olmadığını tespit etmek amacıyla bağımsız örneklemler $t$-testi yapılmış ve sonuçları Tablo 2'de sunulmuştur. Tablo 2'de görüldüğü gibi yapılan bağımsız örneklemler $t$-testi sonucunda kız ve erkek öğrencilerin cebirsel ifadeler konusundaki sözelden cebire geçiş [ $t(178)=-.096, p>.05]$, cebirden sözele geçiş $[t(178)=-.469, p>.05]$, cebirsel ifadelerde toplama ve çıkarma $[t(178)=$ -1.401, $p>.05]$, 1.dereceden bir bilinmeyenli denklem çözümü [t $(178)=-.486, p>.05]$, cebirsel ifadeleri farklı biçimde yazma $[t(178)=-.486, \mathrm{p}>.05]$, değişkene farklı değerler verip hesaplama $[t(178)=.498, p>.05]$ ve basit cebirsel ve görsel ifadeleri açılama $[t(178)=-$ $.946, p>.05$ ] performansları bakımından anlamlı bir fark saptanmamıştır. Ayrıca erkek $(\bar{x}=14.90, \mathrm{SS}=5.86)$ ve kız $(\bar{x}=14.27, \mathrm{SS}=5.79)$ öğrencilerinin CBT başarı performansları arasında anlamlı bir fark saptanmamıştır $[t(178)=-.721, p>.05]$. Bu durum öğrencilerin CBT başarı performanslarının cinsiyet değişkeni bakımından farklılaşmadığını göstermektedir. 
Tablo 2. Öğrencilerin CBT Puanlarının Cinsiyete Göre t-Testi Sonuçları

\begin{tabular}{llcccccc}
\hline CBT'nin Alt Boyutları & Cinsiyet & $\mathbf{n}$ & $\bar{x}$ & SS & sd & $\boldsymbol{t}$ & $\boldsymbol{p}$ \\
\hline Sözelden cebire geçiş & Kiz & 87 & 2.26 & .98 & 178 & -.096 & .923 \\
& Erkek & 93 & 2.28 & 1.12 & & & \\
\hline Cebirden sözele geçiş & Kiz & 87 & 2.00 & 1.24 & 178 & -.469 & .640 \\
& Erkek & 93 & 2.08 & 1.21 & & & \\
\hline Cebirsel ifadelerde toplama ve & Kiz & 87 & 2.22 & 1.04 & 178 & -1.401 & .163 \\
çıkarma & Erkek & 93 & 2.45 & 1.07 & & & \\
\hline 1. dereceden bir bilinmeyenli & Kiz & 87 & 1.98 & 1.31 & 178 & -.486 & .628 \\
denklem çözümü & Erkek & 93 & 2.09 & 1.37 & & & \\
\hline Cebirsel ifadeleri farklı biçimde & Kız & 87 & 1.83 & 1.32 & 178 & -.598 & .551 \\
yazma & Erkek & 93 & 1.95 & 1.35 & & & \\
\hline Değişkene ait farklı değerleri & Kız & 87 & 2.28 & 1.13 & 178 & .498 & .619 \\
hesaplama & Erkek & 93 & 2.19 & 1.37 & & & \\
\hline Basit cebirsel ve görsel ifadeleri & Kız & 87 & 1.71 & 1.14 & 178 & -.946 & .346 \\
açılama & Erkek & 93 & 1.83 & 1.12 & & & \\
\hline CBT’nin Tümü & Kız & 87 & 14.27 & 5.79 & 178 & -.721 & .472 \\
\hline
\end{tabular}

\section{Öğrencilerinin Sınıf Düzeyine Göre CBT Başarı Performanslarına İlişkin Bulgular}

Ortaokul öğrencilerin CBT puanlarının sınıf düzeyi bakımından anlamlı bir fark olup olmadığını tespit etmek amacıyla bağımsız örneklemler $t$-testi yapılmış ve sonuçları Tablo 3 'te sunulmuştur.

Tablo 3. Öğrencilerin CBT Puanlarının Sınıf Bakımından t-Testi Sonuçları

\begin{tabular}{|c|c|c|c|c|c|c|c|}
\hline CBT'nin Alt Boyutları & Sinıf & $\mathbf{n}$ & $\bar{x}$ & SS & sd & $t$ & $p$ \\
\hline \multirow[t]{2}{*}{ Sözelden cebire geçiş } & 7. sinif & 90 & 2.15 & 1.03 & 178 & -1.487 & .139 \\
\hline & 8. sinif & 90 & 2.38 & 1.07 & & & \\
\hline \multirow[t]{2}{*}{ Cebirden sözele geçiş } & 7. sinif & 90 & 1.87 & 1.16 & 178 & -1.834 & .068 \\
\hline & 8. sinif & 90 & 2.21 & 1.26 & & & \\
\hline \multirow{2}{*}{$\begin{array}{l}\text { Cebirsel ifadelerde toplama ve } \\
\text { çkarma }\end{array}$} & 7. sinif & 90 & 2.24 & 0.99 & 178 & -1.263 & .208 \\
\hline & 8. sinif & 90 & 2.44 & 1.12 & & & \\
\hline \multirow{2}{*}{$\begin{array}{l}\text { 1. dereceden bir bilinmeyenli } \\
\text { denklem çözümü }\end{array}$} & 7. $\sin 1 f$ & 90 & 2.00 & 1.29 & 178 & -.388 & .699 \\
\hline & 8. sinif & 90 & 2.07 & 1.40 & & & \\
\hline \multirow{2}{*}{$\begin{array}{l}\text { Cebirsel ifadeleri farklı biçimde } \\
\text { yazma }\end{array}$} & 7. sinif & 90 & 1.74 & 1.26 & 178 & -1.464 & .145 \\
\hline & 8. sinif & 90 & 2.03 & 1.37 & & & \\
\hline \multirow{2}{*}{$\begin{array}{l}\text { Değişkene ait farklı değerleri } \\
\text { hesaplama }\end{array}$} & 7. sinif & 90 & 2.11 & 1.16 & 178 & -1.363 & .175 \\
\hline & 8. sinif & 90 & 2.36 & 1.34 & & & \\
\hline \multirow{2}{*}{$\begin{array}{l}\text { Basit cebirsel ve görsel ifadeleri } \\
\text { açiklama }\end{array}$} & 7. sinif & 90 & 1.62 & 1.08 & 178 & -1.788 & .076 \\
\hline & 8. sinif & 90 & 1.92 & 1.16 & & & \\
\hline \multirow{2}{*}{ CBT’nin Tümü } & 7. sinif & 90 & 13.73 & 5.05 & 178 & -2.013 & .046 \\
\hline & 8. sinif & 90 & 15.46 & 6.41 & & & \\
\hline
\end{tabular}

Tablo 3 incelendiğinde 8.sınıf öğrencilerinin 7.sınıf öğrencilerine göre CBT alt boyutlarına ilişkin performanslarının daha yüksek olduğu, ancak yapılan bağımsız örneklemler $t$-testi sonucunda 7.sınıf ve 8.sinıf ortaokul öğrencilerin CBT'ne ilişkin sözelden cebire geçiş [t $(178)=-1.487, p>.05]$, cebirden sözele geçiş $[t(178)=-1.834, p>.05]$, cebirsel ifadelerde toplama ve çıkarma $[t(178)=-1.263 \mathrm{p}>.05]$, 1.dereceden bir bilinmeyenli denklem çözümü $[t$ $(178)=-.388, p>.05]$, cebirsel ifadeleri farkl biçimde yazma $[t(178)=-1.464, \mathrm{p}>.05]$, değişkene ait farklı değerleri hesaplama $[t(178)=-1.363, p>.05]$ ile basit cebirsel ve görsel ifadeleri açılama $[t(178)=-1.788, p>.05]$ alt boyutlanı bakımından başarı performansları 
arasında anlamlı bir fark saptanmamıştır. Buna karşın 8.sınıf $(\bar{x}=15.46, \mathrm{SS}=6.41)$ ve $7 . \operatorname{sinıf}$ $(\bar{x}=13.73, \mathrm{SS}=5.05)$ öğrencilerinin CBT performansları arasında 8.sınıf öğrenciler lehine anlamlı bir fark saptanmıştır $[t(178)=-2.013, p<.05]$. Bu durum ortaokul öğrencilerin CBT performanslarının 8.sınıf lehine farklılaştığını göstermektedir.

\section{Öğrencilerinin CBT Performansları İle Matematik Başarıları Arasındaki İlişkiye Ait Bulgular}

Yedinci ve sekizinci sınıf öğrencilerin CBT performansları ile matematik dersi karne başarı puanları arasındaki anlamlı bir ilişki olup almadığını belirlemek amacıyla Pearson korelasyon testi yapılmış, sonuçlar Tablo 4'te sunulmuştur.

Tablo 4. Pearson Korelasyon Testi Sonuçları $(n=180)$

\begin{tabular}{|c|c|c|c|c|c|c|c|c|c|c|c|}
\hline Değişken & $\bar{x}$ & SS & 1 & 2 & 3 & 4 & 5 & 6 & 7 & 8 & 9 \\
\hline 1. Başarı Notu & 3.53 & 1.30 & 1 & $.44^{* *}$ & $.46^{* *}$ & $.47^{* * *}$ & $.56^{* *}$ & $.47^{* *}$ & $.55^{* *}$ & $.45^{* *}$ & $.71^{* * *}$ \\
\hline 2. Sözelden Cebire Geçiş & 2.72 & 1.06 & & 1 & $.34^{* *}$ & $.29^{* *}$ & $.29^{* *}$ & $.23^{* *}$ & $.34^{* *}$ & $.19^{* *}$ & $.53^{* *}$ \\
\hline 3. Cebirden Sözele Geçiş & 2.04 & 1.23 & & & 1 & $.480^{* *}$ & $.58^{* *}$ & $.31^{* *}$ & $.39^{* *}$ & $.38^{* *}$ & $.72^{* *}$ \\
\hline 4. Toplama ve Çıkarma & 2.34 & 1.06 & & & & 1 & $.52^{* *}$ & $.30^{* *}$ & $.52^{* *}$ & $.45^{* *}$ & $.72^{* *}$ \\
\hline 5. Denklem Çözümü & 2.03 & 1.34 & & & & & 1 & $.36^{* *}$ & $.59^{* *}$ & $.40^{* *}$ & $.79^{* *}$ \\
\hline 6. Farklı Biç. Yazma & 1.88 & 1.32 & & & & & & 1 & $.33^{* *}$ & $.42^{* *}$ & $.63^{* *}$ \\
\hline 7. Değer Hesaplama & 2.23 & 1.26 & & & & & & & 1 & $.42^{* *}$ & $.75^{* *}$ \\
\hline 8. Cebirsel ve Görsel İfade & 1.77 & 1.13 & & & & & & & & 1 & $.67^{* *}$ \\
\hline 9. $\mathrm{CBT}$ & 14.60 & 5.82 & & & & & & & & & 1 \\
\hline
\end{tabular}

1: Matematik başarı notu, 2: Sözel ifadeden cebire geçiş, 3: Cebirden sözel ifadeye geçiş, 4: Cebirsel ifadelerde toplama ve çıkarma, 5: Bir dereceden bir bilinmeyenli denklem çözümü, 6: Cebirsel ifadeleri farklı biçimde yazma, 7: Değişkene ait farklı değerleri hesaplama, 8: Basit cebirsel ve görsel ifadeleri açıklama, 9: Cebirsel ifadeler başarı testi (CBT)

Tablo 4'de görüldüğü gibi Pearson korelasyon testi sonucunda öğrencilerin matematik dersi başarı notlarıyla ( $\bar{x}=3.53, \mathrm{SS}=1.30)$ ile CBT’ye ilişkin sözelden cebire geçiş $[r=.446, p$ $<.01]$, cebirden sözele geçiş $[r=.464, p<.01]$, cebirsel ifadelerde toplama ve çıkarma $[r=$ $.475, p<.01]$, 1.dereceden bir bilinmeyenli denklem çözümü $[r=.564, p<.01]$, cebirsel ifadeleri farklı biçimde yazma $[r=.475, p<.01]$, değişkene ait farklı değerleri hesaplama $[r=$ $.558, p<.01]$ ile basit cebirsel ve görsel ifadeleri açıklama $[r=.459, p<.01]$ alt boyutları bakımından başarı performansları arasında pozitif yönlü orta düzeyde anlamlı bir ilişki saptanmıştır. Ayrıca öğrencilerin matematik dersi başarı notlarıyla $(\bar{x}=3.53, \mathrm{SS}=1.30)$ ile CBT'ye ilişkin performansları $(\bar{x}=14.60, \mathrm{SS}=5.82)$ arasında pozitif yönlü yüksek düzeyde anlamlı bir ilişki olduğu saptanmıştır $[r=.714, p<.01]$. Bu durum yedinci ve sekizinci sınıf öğrencilerin cebirsel ifadeler konusundaki öğrenme düzeylerinin ve başarılarının matematik dersi başarısını doğrudan etkilediğini göstermektedir.

\section{Tartışma ve Sonuç}

$\mathrm{Bu}$ araştırma kapsamında 8.sınıf öğrencilerinin cebirsel ifadeler konusunda en başarılı oldukları alanlara arasında "cebirsel ifadede değişkene ait farklı değerleri hesaplama" ve "cebirsel ifadelerde toplama ve çıkarma" olduğu, en başarısız oldukları alanlara arasında "görsel ve 
cebirsel ifadelerin anlamını açıklama" ve "cebirsel ifadeleri farklı biçimde yazma" olduğu tespit edilmiştir. $\mathrm{Bu}$ durum matematik öğretmenlerinin derslerde daha çok cebirsel denklemler konusunda aritmetik işlem boyutunu ön plana çıkardıkları, görsel ve cebirsel ifadeleri farklı gösterim türleri arasındaki geçişlere yeterince yer vermedikleri şeklinde yorumlanabilir. Nitekim yapılan bazı araştırmalar (Akkaya ve Durmuş, 2006; Burill, 2002; Ersoy ve Erbaş, 2000; Macgregor ve Stacey, 1997; Perso, 1992) öğrencilerin daha çok görsel ifade içeren cebirsel problemlerde daha başarısız olduklarını ortaya koymaktadır. Bu yönüyle bu araştırmanın bulgusuyla uyum göstermektedir.

Yapılan bu araştırma sonucunda, öğrencilerin cebirsel ifadelerle dört işlem yapma becerisinde gösterdikleri başarıyı, birinci dereceden bir bilinmeyenli denklem çözme ve cebirsel ifadelerin farklı gösterim türleri (cebirsel, sözel ve görsel) arasındaki geçiş yapma becerilerinde gösteremedikleri tespit edilmiştir. Bu durum öğrencilerin cebirsel ifadeler konusunda işlemsel ve kavramsal bilgi düzeylerinin dengelenmediğini, cebirsel ifadeler konusunda kavramsal düzeyde öğrenmenin yeterince gerçekleşmediğini göstermektedir. Bunun nedenleri arasında cebirsel ifadeler konusunda cebirsel işlem odaklı, tek yönlü ve belli kalıplara dayalı öğretmen merkezli geleneksel öğretiminin daha çok tercih edilmesi gösterilebilir. Nitekim ülkemizde cebir öğretiminde daha çok işlem, kural ve formüllerin ezberlendiği (Akkan, 2010; Baki ve Kartal, 2004), işlemsel ve algoritmaya dayalı öğrenmenin özendirildiği bunun cebir konusunda kavramsal öğrenmeye ve aritmetikten cebire geçişi engellediği (Akkan ve Baki, 2016; Yıldızhan ve Şengül, 2017), öğrencilerin cebirsel ifadeler konusunda birçok hata ve kavram yanılgısına sahip olduğu (Akkaya ve Durmuş, 2006; Ersoy ve Erbaş, 2005; Gürel ve Okur, 2017; Kaya ve diğ., 2016; Oktaç, 2010; Yenilmez ve Avcu, 2009; Yıldız, Çiftçi, Akar ve Sezer; 2015) ifade edilmektedir. Bu yönüyle bu araştırmanın sonucunu destekler niteliktedir.

Diğer taraftan daha önce yapılan bazı araştırmalar öğrencilerin sözel bir ifadeyi cebirsel ifadeye dönüştürmede zorlandıklarını göstermesine karşın (Herscovics ve Linchevski, 1994; MacGregor ve Stacey, 1997), bu araştırmada öğrencilerin sözelden cebire geçiş performanslarının ortalamanın üzerinde olduğu belirlenmiştir. Bu durum 2013 yılında güncellenen matematik öğretim programında yer alan bu türden etkinliklerin öğrencilerin sözel ifadeyi cebirsel ifadeye dönüştürme başarılarına olumlu yönde katkı sağladığı şeklinde yorumlanabilir.

Ayrıca bu araştırmada bazı öğrencilerin, harflerin değerlerinin alfabedeki sırasına göre arttığını düşündükleri belirlenmiştir. Bu sonuç, daha önce bulunan araştırma sonuçlarıyla paralellik göstermektedir (Akkaya ve Durmuş, 2006; MacGregor ve Stacey, 1994; Perso, 1992). Öğrencilerde görülen bir diğer kavram yanılgısı ise harfli ifadelerle denklem çözerken ve işlem yaparken işlem önceliğine ve paranteze dikkat etmemeleridir. Benzer şekilde yapılan birçok araştırma sonuçları da bu yanılgıyı destekler niteliktedir (Akkaya ve Durmuş, 2006; Akyüz ve Hangül, 2014; Baysal, 2010; Gürel ve Okur, 2017; Yenilmez ve Avcu, 2009; Yıldız ve diğ., 2015; Yıldızhan ve Şengül, 2017). Diğer taraftan bu araştırmada, bazı öğrencilerin toplananın yer değiştirmesinde hata yaparak birinci dereceden bir bilinmeyenli denklemleri yanlış yaptıkları ortaya çıkmıştır. Bu öğrencilerin, denklem çözümünde bilinmeyenin ya da sayının işaretine dikkat etmeden eşitliğin tarafları arasında yer değiştirdikleri görülmüştür. Kieran'a (1992) göre, bu hatanın denklem çözerken, denklemde eşitliğin korunumu gereği denklemin bir tarafına uygulanan işlemin diğer tarafa da uygulanması mantığını kavramak yerine, öğrencilerin 
terimleri eşitliğin diğer tarafına zit işaretle geçirme yöntemini ezberlemelerinden kaynaklandığını belirtmiştir. Benzer şekilde Şimşek ve Soylu (2018) yaptıkları araştırmada yedinci sınıf öğrencilerinin cebirsel ifadeler konusunda değişkeni görmezden gelme, verilen cebirsel ifadeyi denkleme dönüştürerek çözme, soruda verilen değişken yerine $x$ değiş̧kenini kullanma ve verilen probleme uygun denklemi yanlış kurma gibi nedenlerden dolayı hata yaptıklarını belirlemişlerdir. Erdem (2013) de yaptığı araştırmasında 7.sınıf öğrencilerin değişkenler arası kat ilişkini oluşturamama, negatif katsayıyı görmezden gelme, eşitliğin bir tarafindan diğer tarafına terimi işaret değiştirmeden geçirme, işlem önceliğine dikkat etmeden soldan sağa doğru işlem yapma şeklinde kavram yanılgılarına sahip olduklarını saptamıştır.

Geleneksel yaklaşıma göre cebirsel muhakemeye ulaşmak için aritmetik düşüncenin aşılması gerekmektedir, oysa günümüzde bazı araştırmacılara göre cebirsel muhakeme ile aritmetik düşünce birlikte gelişim göstermektedir (Blanton ve Kaput, 2005; Gürbüz ve Akkan, 2008). Elde edilen sonuçlara göre istenilen cebirsel muhakeme seviyesine ulaşllamamıştır. Özellikle görsel ifadeler ve bilinmeyen kavramı öğrencilerde halen kargaşa yaratmaktadır. Oktaç'a (2010) göre, aritmetiği işlem merkezli öğrenen öğrenciler, oradaki alışkanlıklarını cebire de taşıdıkları için, denklemlerde gördükleri eşitlik işaretini işlem yaparak sonuç elde etmeye çalışıyorlar ki bu da bir kavram yanılgısıdır. Bu yanılgıyı önlemek için öğretmenlerin, eşitlik kavramını çözülmesi gereken bir problem gibi değil; eşitliğin tarafları arasındaki dengeyi temsil ettiğini öğrencilere kazandırması gerekir. Bu sebeple denklik ve denge kavramı ilk olarak aritmetikte kazandırılmalı, daha sonra cebire transfer edilmelidir. Bunun için çeşitli modellerden yararlanılabilir (Baratta, 2011). Yeni öğretim programı çerçevesinde MEB tarafından hazırlanan ders kitapları da bu kapsamda hazırlanmış ve öğrencilerin denklem çözümlerine geçmeden denklik kavramını anlamaları hedeflenmiştir (MEB, 2018).

$\mathrm{Bu}$ araştırmada öğrenim seviyesi arttıkça 8 .sınıf öğrencilerin 7. sınıf öğrencilerine nazaran cebirsel ifadeler konusundaki performanslarının kısmen artış olduğu belirlenmiştir. Yapılan analiz sonucunda 8.sınıf öğrencilerin CBT performanslarının 7.sınıf öğrencilerine göre anlamlı olarak farklılaşırken, CBT alt boyutları ait performansları arasında anlamlı fark saptanmamıştır. $\mathrm{Bu}$ sonuç öğrenim düzeyinin artmasının öğrencinin cebirsel düşünme becerilerinde beklenen düzeyde artış sağlamadığını göstermektedir. Benzer şekilde Akkan ve Baki (2016) ile Akkan ve diğerleri (2012) yaptıkları araştırmalarda ortaokul öğrencilerin öğrenim seviyeleri arttıkça cebir konusundaki başarılarındaki artışın çok az olduğunu belirlemişlerdir. $\mathrm{Bu}$ durum öğrencilerin sembolleştirme yerine aritmetik çözüm yolları kullanmaya devam ederek, cebirsel muhakeme ve işlem yapabilme yeteneğini ortaokul seviyesinde beklenen düzeye taşıyamadıkları şeklinde yorumlanmıştır. Bu yönüyle bu araştırmanın bulgusunu desteklemektedir.

$\mathrm{Bu}$ araştırmada kız ve erkek öğrencilerin cebir başarı testinin tümü ve alt boyutlarındaki performansları arasında anlamlı fark olmadığı saptanmıştır. Bu durum öğrencilerin cebir başarı testi performanslarının cinsiyet bakımından farklılaşmadığını ve benzer başarı düzeyine sahip olduklarını göstermiştir. Elde edilen bu sonuç, Erbaş ve Ersoy'un (2002) 9.sınıf öğrencileri ile Küpcü ve Yaprak Ceylan'ın (2012) ortaokul 8.sınıf öğrencileri ile yaptıkları araştırmada kız ve erkek öğrencilerin cebir başarıları arasında anlamalı fark göstermediği sonuçlarıyla paralellik gösterirken, Kaya'nın (2017) yedinci sınıf öğrencileri ile yürüttüğü araştırmada öğrencilerin cebirsel düşünme becerilerinin düşük düzeyde olmalarına karşın, kızların erkeklere göre daha 
başarılı oldukları sonucuyla ile örtüşmemektedir. Bu araştırmada 7.sınıf ve 8.sınıf öğrencilerinin matematik dersi başarı notlarıyla ile cebirsel ifadeler başarı testine ilişkin performansları arasında pozitif yönlü orta düzeyde anlamlı bir ilişsi olduğu saptanmıştır. Bu durum öğrencilerin cebirsel ifadeler konusundaki öğrenme düzeylerinin ve başarılarının matematik dersi başarısını doğrudan etkilediğini göstermektedir. Benzer şekilde yapılan bazı araştırmalar (Akkaya ve Durmuş, 2006; Umay, 2003; Yenilmez ve Avcu, 2009) cebirsel düşünme becerisi ile matematik başarıları arasında pozitif yönlü anlamlı ilişki olduğunu göstermiştir. Akkaya ve Durmuş (2006) çalışmalarında cebirsel muhakemesi gelişen öğrencilerin daha az kavram yanılgısına sahip olduklarını saptamıştır. Yakar ve Yılmaz (2017) da gerçek yaşam durumunu matematiksel ifadeye dönüştürme sürecindeki matematiksel dil becerilerini inceledikleri çalışmalarında matematik başarı düzeyi yüksek olan öğrencinin ifadeleri açıklarken doğru sözel, yazılı ve sembolik dil kullandığı gözlemlenmiştir. Matematik başarı düzeyi düşük olan öğrencinin ise gerçek yaşam durumlarını açıklarken ve sembolik ifadeleri oluştururken zorlandığ düşünme becerilerinin artırılmasına önem verilmesi gerektiği ifade edilebilir. Nitekim son yıllarda alanyazında (Akkan ve Baki, 2016; Gülpek, 2006; Kaya ve Keşan, 2014; Yıldız ve diğ., 2015), matematik öğretim programlarında (MEB, 2013; 2018) ve reform çalışmalarında (NCTM, 2000) cebirsel düşünme becerisinin geliştirilmesi gerektiği vurgulanmaktadır. Buna karşın bu araştırmanın bulguları öğrencilerin cebirsel ifadeler konusunu kavramsal düzeyde öğrenmediklerini, aritmetikten cebire geçişte zorlandıklarını göstermekte, cebir öğretiminde ciddi sorunlar olduğunu işaret etmektedir. Bu nedenle cebir öğretiminde işlemsel öğrenme odaklı geleneksel öğretim yerine aritmetikten cebire geçişi kolaylaştıran somut materyal ve görsellerin kullanılması, cebirsel muhakeme becerilerini kolaylaştıran öğrenci merkezli öğretim etkinliklerin ön plana çıkartılması önerilir. Bununla birlikte cebirsel ifadeler konusunda oluşabilecek muhtemel hata ve kavram yanılgılarına ilişkin örneklerin öğrencilerin etkin katılımı ile sınıf içinde tartışılması faydalı olacaktır.

$\mathrm{Bu}$ araştırmada ortaokul 7.sınıf ve 8.sınıf öğrencilerinin cebirsel ifadeler konusundaki başarı performansları karşılaştırmalı olarak incelenmiştir. Bundan sonra yapılacak araştırmalarda cebirsel ifadeler konusundaki hata ve havram yanılgıları görüşme tekniği kullanılarak detaylı olarak incelenebilir. 


\section{Kaynakça}

Akarsu, E. (2013). 7.sınıf öğrencilerinin cebir ögrenme alanında matematiksel dil kullanımlarının incelenmesi. (Yayınlanmamış yüksek lisans tezi). Dokuz Eylül Üniversitesi, Eğitim Bilimleri Enstitüsü, İzmir.

Akkan, Y. (2009). İlköğretim öğrencilerinin aritmetikten cebire geçiş süreçlerinin incelenmesi. (Yayınlanmamış doktora tezi). Karadeniz Teknik Üniversitesi, Fen Bilimleri Enstitüsü, Trabzon.

Akkan, Y. ve Baki, A. (2016). Ortaokul öğrencilerinin aritmetikten cebire geçiş süreçlerinin incelenmesi: sembollerin kullanımı ve harflerin anlamı. Bayburt Eğitim Fakültesi Dergisi, 11(2), 270-304.

Akkan, Y., Baki, A., ve Çakıroğlu, Ü. (2012). 5-8. sınıf öğrencilerinin aritmetikten cebire geçiş süreçlerinin problem çözme bağlamında incelenmesi. Hacettepe Üniversitesi Ĕgitim Fakültesi Dergisi, 43, 1-13.

Akkaya, R. ve Durmuş, S. (2006). İlköğretim 6-8.sınıf öğrencilerinin cebir öğrenme alanındaki kavram yanılgıları. Hacettepe Üniversitesi Eğitim Fakültesi Dergisi, 31, 1-12.

Akyüz, G. ve Hangül, T. (2014). 6.sınıf öğrencilerinin denklemler konusunda sahip oldukları yanılgıların giderilmesine yönelik bir çalışma. Kuramsal Ĕğitimbilim Dergisi, 7(1), 16-43.

Arcavi, A. ve Schoenfeld, A. (1988). On the meaning of variable. Mathematics Teacher, 81(6), 420-427.

Baki A. ve Bütüner S. (2013). Cebirin tarihsel gelişimi. Turkish Journal of Computer and Mathematics Education (TURCOMAT), 2(3), 198-231.

Baki, A. ve Kartal, T. (2004). Kavramsal ve işlemsel bilgi bağlamında lise öğrencilerinin cebir bilgilerinin karakterizasyonu. Türk Eğitim Bilimleri Dergisi, 2(1), 27-46.

Baratta, W. (2011). Linear equations: Equivalance=success. Australian Mathematics Teacher, 67(4), 611.

Baysal, F. K. (2010). Ilköğretim öğrencilerinin (4-8.Sınıf) cebir öğrenme alanında oluşturdukları kavram yanılgıları. (Yayınlanmamış yüksek lisans tezi). Abant İzzet Baysal Üniversitesi, Sosyal Bilimler Enstitüsü, Bolu.

Behr, M., Erlwanger, S. \& Nichols, E. (1980). How children view the equal sign. Mathematics Teaching, $92,13-15$

Bernardo, A. \& Okagaki, L. (1994). Roles of symbolic knowledge and problem-information context in solving word problems. Journal of Educational Psychology, 86, 212-220.

Bingölbali, E. \& Özmantar, M. F. (2010). İlköğretimde karşılaşılan matematiksel zorluklar ve çözüm önerileri (2. bs.). Ankara: Pegem Akademi Yayınevi.

Blanton, L. M., \& Kaput, J. J. (2005). Characterizing a classroom practice that promotes algebraic reasoning. Journal for Research in Mathematics Education, 36(5),412-446.

Davidenko, S. (1997). Building the concept of function from students' everday activities. The Mathematics Teache, 90(2),144-149.

Dede, Y. ve Argün, Z. (2003). Cebir, öğrencilere niçin zor gelmektedir? Hacettepe Üniversitesi Ĕgitim Fakültesi Dergisi, 24, 180-185.

Erbaş, A. K. ve Ersoy, Y. (2002). Dokuzuncu sınıf öğrencilerinin eşitliklerin çözümündeki başarıları ve olası kavram yanılgıları. UFBMEK-5 Bildiri Kitabı (ss.16-18). Ankara: Devlet Kitapları Basımevi.

Erdem, Z. Ç. (2013). Ögrencilerin denklem konusundaki hata ve kavram yanılgılarının belirlenmesi ve bu hata ve yanılgıların nedenleri ve giderilmesine ilişkin ögretmen görüşleri. (Yayınlanmış yüksek lisans tezi). Adıyaman Üniversitesi, Fen Bilimleri Enstitüsü, Adıyaman.

Ersoy, Y. ve Erbaş, K. (2005). Kassel projesi cebir testinde bir grup Türk öğrencinin genel başarısı ve öğrenme güçlükleri. İlköğretim Online, 4(1), 18-39.

Falkner, K., Levi, L. \& Carpenter, T. (1999). Children's understanding of equality: A foundation for algebra. Teaching children mathematics, 6(4), 232-236.

Gülpek, P. (2006). Illköğretim 7. ve 8. sinıf öğrencilerinin cebirsel düşünme düzeylerinin gelişimi. (Yayınlanmamış yüksek lisans tezi), Uludağ Üniversitesi, Eğitim Bilimleri Enstitüsü, Bursa. 
Gürbüz, R. \& Toprak, Z. (2014). Aritmetikten cebire geçişi sağlayacak etkinliklerin tasarlanması, uygulanması ve değerlendirilmesi. Necatibey Eğitim Fakültesi Elektronik Fen ve Matematik Eğitimi Dergisi, 8(1), 178-203.

Gürel, Z. Ç. ve Okur, M. (2017). 7. ve 8. sınıf öğrencilerinin eşitlik ve denklem konusundaki kavram yanılgıları. Cumhuriyet Uluslararası Eğitim Dergisi, 6(4), 479-507.

Herscovics, N. \& Linchevski, L. (1994). A cognitive gap between arithmetic and algebra. Educational Studies in Mathematics, 27, 59-78.

Kar, T., Çiltaş, A. ve Işık, A. (2011). Cebirdeki kavramlara yönelik öğrenme güçlükleri üzerine bir çalışma. Kastamonu Eğitim Dergisi, 19(3), 939-952.

Kaya, D. ve Keşan, C. (2014). İlköğretim seviyesindeki öğrenciler için cebirsel düşünme ve cebirsel muhakeme becerisinin önemi. International Journal of New Trends in Arts, Sports \& Science Education, 3(2), 38-47.

Kaya, D. (2017). Yedinci sınıf öğrencilerinin cebirsel düşünme düzeyleri ile becerilerinin incelenmesi. Bartın Üniversitesi Eğitim Fakültesi Dergisi, 6(2), 657-675.

Kaya, D., Keşan, C., İzgiol, D. ve Erkuş, Y. (2016). Yedinci sınıf öğrencilerinin cebirsel muhakeme becerilerine yönelik başarı düzeyi. Turkish Journal of Computer and Mathematics Education (TURCOMAT) , 7 (1) , 142-163. DOI: 10.16949/turcomat.95945

Kieran, C. (1992). The learning and teaching of school algebra. In D.A. Grouws ( Eds.). Handbook of research on mathematics teaching and learning (pp. 390-419). New York: Macmillan.

Kieran, C. \& Chalouh, L. (1993). Prealgebra: The transition from arithmetic to algebra. In Douglas T. Owens (Ed.), Research ideas for the classroom: Middle grades mathematics (pp.178-192). Reston, VA: NCTM

Köroğlu, H., Geçer, Z., Taşçı, Ö., \& Ay, H. G. (2004). İlköğretim 7. sınıf denklemler konusunun farklı öğrenme etkinlikleri ile işlenmesi ve değerlendirilmesi. 6. Ulusal Fen Bilimleri ve Matematik Ĕgitimi Kongresinde sunulmuş bildiri, Marmara Üniversitesi, İstanbul.

Küpcü, A.R. ve Yaprak Ceylan, E. (2012). İlköğretim öğrencilerinin cebir başarısının cebirsel düşünme düzeyi ile cinsiyet arasındaki ilişki, 12-14 Eylül 2012, XXI. Ulusal Eğitim Bilimleri Kongresi, Marmara Üniversitesi, İstanbul.

Linchevski, L. (1995). Algebra with numbers and arithmetic with letters: A definition of pre-algebra. The Journal of Mathematical Behaviour, 14, 113-120.

Linchevski, L. \& Herscovics, N. (1996). Crossing the cognitive gap between arithmetic and algebra: Operating on the unknown in the context of equations. Educational Studies in Mathematics, 30, 38-65.

Londholz, R. D. (1993). The transition from arithmetic to algebra. In E.L. Edwards (Ed), Algebra for everyone (pp. 24-33). Reston, VA: NCTM.

MacGregor, M. \& Stacey, K. (1997). Students' understanding of algebraic notation: 11-16. Educational Studies in Mathematics, 33, 1-19.

Milli Eğitim Bakanlığı (MEB) (2013). Ortaokul matematik dersi (5, 6, 7 ve 8. Sinıflar) öğretim programı. Ankara: MEB.

Milli Eğitim Bakanlığı (MEB) (2018). Matematik dersi öğretim programı (İlkokul ve Ortaokul 1, 2, 3, 4 , 5, 6, 7 ve 8. Sinuflar). Ankara: MEB.

National Council of Teachers of Mathematics (NCTM) (2000). Principles and standards for school mathematics. Reston, VA: NCTM

Oktaç, A. (2010). Birinci dereceden tek bilinmeyenli denklemler ile ilgili kavram yanılgıları. E. Bingölbali \& M. F. Özmantar (Eds) içinde, Matematiksel zorluklar ve çözüm önerileri (ss.241262). Ankara: Pegem Akademi Yayınevi.

Perso, T. (1992). Using diagnostic teaching to overcome misconceptions in algebra. The Mathematical Association of Western Australia. 
Şimşek, B. ve Soylu, Y. (2018). Ortaokul 7. sınıf öğrencilerinin cebirsel ifadeler konusunda yaptıkları hataların nedenlerinin incelenmesi. Journal of International Social Research, 11(59), 830-848.

Umay, A. (2003). Matematiksel muhakeme yeteneği. Hacettepe Üniversitesi Eğitim Fakültesi Dergisi, 24, 234-243.

Van Amerom, B. A. (2002). Reinvention of early algebra: Developmental research on the transition from arithmetic to algebra. (Unpublished doctoral dissertation). University of Utrecht, The Netherlands.

Yakar, A. E. ve Yılmaz, S. (2017). 7. sınıf öğrencilerinin cebire yönelik gerçek yaşam durumlarını matematiksel ifadelere dönüştürme sürecindeki matematiksel dil becerileri. İnönü Üniversitesi Ĕ̈itim Fakültesi Dergisi, 18 (1), 292-310.

Yenilmez, K. ve Avcu, T. (2009). Altıncı sınıf öğrencilerinin cebir öğrenme alanındaki başarı düzeyleri. Ahi Evran Üniversitesi Ĕ̈itim Fakültesi Dergisi, 10(2), 37-45.

Yıldız, P., Çiftçi, Ş. K., Akar, Ş. ve Sezer, E. (2015). Ortaokul 7. sınıf öğrencilerinin cebirsel ifadeleri ve değişkenleri yorumlama sürecinde yaptıkları hatalar. Hacettepe Üniversitesi Eğitim Araştırmaları Dergisi, 1(1), 18-31.

Yıldızhan, B. ve Şengül, S. (2017). 6. sınıf öğrencilerinin harflerin anlamına yönelik kavram yanılgılarının aritmetikten cebire geçiş süreci bağlamında incelenmesi ve öğrencilerin matematik tutumları ve öz yeterlikleri ile karşılaştırılması. The Journal of International Lingual Social and Educational Sciences, 3(2), 249-268. 


\section{Ek-1. Ölçme Aracında Yer Alan Örnek Sorular}

1) Ceren, kırtasiyeden tanesi 3 TL olan kalemlerden ve tanesi 2 TL olan silgilerden alıyor.

$\boldsymbol{k}$ : aldığı kalemlerin sayısını;

$s:$ aldığı silgilerin sayısını göstermektedir.

Ceren, kasaya 15 TL ödediğine göre aşağıdakilerden hangisi doğrudur?
A) $3 s+2 k=15 \mathrm{TL}$
B) $k+s=15 \mathrm{TL}$
C) $3 k+2 s=15 \mathrm{TL}$
D) $6 k+s=15 \mathrm{TL}$

2) 4 . $(x-7)$ cebirsel ifadesi için aşağıdaki cümlelerden hangisi olamaz?
A) Bir sınıftaki öğrencilerin 7 eksiğinin 4 katı
B) 7 TL zararla satılan bir üründen 4 tane satılmasıyla elde edilen para
C) 7 yumurta kırıldıktan sonra, kalanların 4 katı
D) Okula gelirken attığım adım sayısının 4 katının 7 eksiği

3) $3 c+7 c=$ ? işleminin sonucu nedir?
A) 10 ceviz
B) $3 c+7 c$
C) $10 c$
D) 100

4)

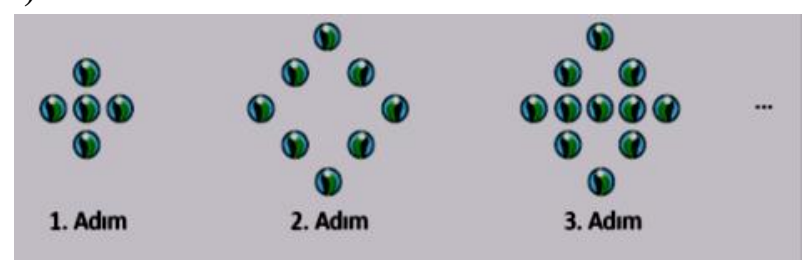

Yukarıda ilk 3 adımı verilen örüntünün kuralı nasıl ifade edilebilir?
A) $5 n$
B) $3 n$
C) $3 n+5$
D) $3 n+2$

5) Ĕger $2 x y=240$ ve $x=4$ ise $y=$ ?
A) 0
B) 1
C) 30
D) 60

6) $12-2 x=4 x+3$ ise $x=$ ?
A) $x=\frac{15}{12}$
B) $x=\frac{15}{16}$
C) $x=\frac{9}{6}$
D) $x=\frac{10}{7}$

7) '3.n' ve ' $n+3$ ' ifadelerin büyüklüğü hakkında ne söylenebilir?
A) '3.n' büyüktür.
B) ' $n+3$ ' büyüktür.
C) İkisi birbirine eşittir.
D) " $n$ ” ye bağlı olarak değişir. 


\section{Extended Abstract}

\section{Introduction}

Algebra, which is an important area of mathematics, contributes to the development of student's ability to think algebraically and enhance his or her mathematics reasoning. Furthermore, the ability of abstract thinking and being able to make algebraic operation facilitates students' problem solving processes (Dede \& Argün, 2003; Kieran, 1992). Hence, the teaching of algebra comprises a wide learning area, which includes the topics of algebraic expressions and equations at secondary school and the functions at high school (Kaya \& Keşan, 2014). Therefore, in the mathematics curriculum (The Ministry of National Education, 2013; NCTM, 2000) the algebraic thinking skills are given importance at all grade levels. However, many studies (Akkan, 2009; Akkaya \& Durmuş, 2006; Baki \& Kartal, 2004; Dede, 2004; Ersoy \& Erbaş, 2005; Herscovics \& Linchevski, 1994; Kieran \& Chalouh, 1993; Perso, 1992) have shown that students have difficulty in understanding the concepts of algebra (equality, equations, algebraic expressions, variables, etc.) and have misconceptions.

When the mathematics program which is updated with $4+4+4$ education system is examined in our country, it is aimed that the students who meet algebra at the 6th grade level to carry the skills they gain about the field of algebra learning to secondary education in 7 th and 8th grades. For this reason, there is a need to examine the performance of 7 th and 8 th grade students about algebraic expressions which form the basis of algebraic thinking. The aim of this research is to investigate the performances of 7th and 8th grade students about algebraic expressions. In this context, answers to these questions were sought: (a) What is the level of secondary school students' performances on algebraic expressions? (b) Do the performances of secondary school students on algebraic expressions show significant difference in terms of gender and grade? (c) Is there a significant relationship between the achievement performance of secondary school students on algebraic expressions and their achievement in mathematics?

\section{Method}

This research was conducted using survey methods. The study group consisted of 180 secondary school students randomly selected in the seventh $(\mathrm{n}=90)$ and eighth grade $(\mathrm{n}=90)$ students in Afyonkarahisar province. 28-multiple choice questions algebra test was used as data collection tool. In this research, algebra tests consisted of 28 multiple choice questions and developed by researchers were used as data collection tools. In the process of developing the algebra test, the studies in the literature (Akkaya \& Durmuş, 2006; Ersoy \& Erbaş, 2005; Perso, 1992) were used. In the development of the algebra test, gains and skills related to the algebra learning in 2013 mathematics curriculum were taken into consideration. These gains are respectively, "Algebraic expression appropriate for a situation presented orally," "Writing an oral situation that complies with the algebraic expression," "Adding and subtracting with algebraic expressions," "Solving first degree equations with one unknown," Understanding simple algebraic expressions and writing them in different ways," "Calculating the value of algebraic expression for different natural number values that the variable will have," "Explaining the meanings of simple visual and algebraic expressions." The algebra test was composed of 7 subdimensions based on these skills and there were 4 multiple choice questions in each dimension. For the correct answers given to each question in the algebra test, 1 point, false and null answers 
were given zero score and students' algebra performance scores were obtained. The KR-20 reliability coefficient of the algebra test was calculated as 0.84 . SPSS 17.0 package program was used in the analysis of the obtained data and independent samples t-test and one-way ANOVA test and Pearson correlations test were performed depending on the variables.

\section{Results and Conclusion}

In this research, it was found that 7th and 8th grade students showed the best performance regarding algebraic expressions in "the ability to add and subtract in algebraic expressions" $(M$ $=2.34, S D=1.06$ ) and the worst performance in the ability to "explain simple algebraic and visual expressions" $(M=1.77, S D=1.13)$. While the students were more successful with questions in which arithmetical operations were at the forefront, it was determined that they were less successful with questions that necessitate visualization. Their general success performances regarding algebraic expressions were found to be at "medium-level" $(M=14.60$, $S D=5.82$ ). As a result of the independent $t$-test, no significant difference was found between the success performances of girls $(M=14.27, S D=5.79)$ and boys $(M=14.90, S D=5.86)$ regarding algebraic expressions $[t(178)=-.721, p>.05]$. While no significant difference was found between the algebra success performances of 7th and 8th grade students with respect to the sub-dimensions of the algebra test, a significant difference was found in favour of 8 th grade students among the general performances regarding the algebra test $[t(178)=-2.013, p<.05]$. In addition, it was found that there was a positive medium-level significant relationship between the students' math class grades and their performances regarding algebraic expressions success test $[r=.714, p<.01]$. Similarly, some studies conducted (Akkaya \& Durmuş, 2006; Umay, 2003; Yenilmez \& Avcu, 2009) have shown that there is a positive significant relationship between the students' algebraic thinking ability and their success in math. In this respect, it could be stated that increasing students' algebraic thinking ability should be emphasized in order to increase their success in maths.

As a result of this study, it was found that the students did not succeed in their abilities to solve first degree equations with one unknown and change over to different projection types (algebraic, oral and visual) of algebraic expressions as they did regarding their ability to perform four operations with algebraic expressions. This situation has revealed that students' operational and conceptual knowledge levels were not adequately balanced regarding algebraic expressions and that learning in conceptual level did not develop adequately in terms of algebraic expressions. The predominant preference of algebraic operation oriented, unidirectional and teacher centred traditional teaching based on certain patterns may be shown among its reasons. Hence, it has been expressed that mainly operations, rules and formulas are memorised, operational learning and algorithm based learning is encouraged in our country (Akkan, 2010; Baki \& Kartal, 2004) and that this hinders conceptual learning regarding algebra and transition from arithmetic to algebra (Akkan \& Baki, 2016; Yıldızhan \& Şengül, 2017; Yıldız, Çiftçi, Akar \& Sezer, 2015), that students make many mistakes and have misconceptions regarding algebraic expressions (Akkaya \& Durmuş, 2006; Ersoy \& Erbaş, 2005; Gürel \& Okur, 2017; Kaya et al., 2016; Oktaç, 2010; Yenilmez \& Avcu, 2009; Y1ldız et al., 2015). In this regard, it supports the results of this research.

As a result, it was found that the performances of students regarding algebraic expressions partially increased parallel to the level of learning. On the other hand, it was 
determined that students had more difficulty in interpreting algebraic expressions presented visually whereas they were more successful with algebraic expressions that necessitate arithmetical operation. It is believed that this situation results from the inability to reach the desired levels in the transition from arithmetic to algebra in algebra teaching starting at the sixth grade in our country. In this respect, further utilization of concrete materials and visuals in algebra teaching is suggested in order to ease transition from arithmetic to algebra. In addition, it will be useful to discuss examples of possible errors and misconceptions about algebraic expressions. 